\title{
THE LEVEL OF VITAMIN A AND CAROTENE IN THE PLASMA OF RHEUMATIC SUBJECTS .
}

\author{
By ROBERT E. SHANK,1 ALVIN F. COBURN, LUCILE V. MOORE, \\ AND CHARLES L. HOAGLAND \\ (From the United States Navy Research Unit ${ }^{2}$ at the Hospital of The Rockefeller Institute for Medical \\ Research and from the Department of Medicine, Columbia University College of \\ Physicians and Surgeons, and the Presbyterian Hospital, New York)
}

(Received for publication April 15, 1943)

It is recognized that rheumatic fever occurs more frequently in individuals from low income groups than in those from economic groups with greater income. In a recent study (1), the diets of 50 rheumatic children from families of low income were analyzed and compared with those of 50 non-rheumatic children from families on high income. Striking differences were found. The diets of the rheumatic children contained less than required amounts of various food components, with most marked inadequacies of protein, iron, and vitamin A. The occurrence of inadequate intake of vitamin $A$ was much more frequent in the rheumatic than in the nonrheumatic children, only 2 of the former and 36 of the latter having diets deficient in this component. There was a statistically significant association between susceptibility to rheumatic fever and inadequate intake of vitamin A. In the half of the rheumatic group considered most susceptible to rheumatic fever, only one child received vitamin $A$ in required amounts. An analysis of the diet in terms of units of vitamin A obtained from animal and plant sources revealed the following facts: (a) children most susceptible to rheumatic fever received an average of 2280 I.U.4 from animal and 2340 I.U. from vegetable sources, daily; (b) corresponding values for children less susceptible to rheumatic fever were 4840 I.U. and 4900 I.U., respectively; (c) nonrheumatic children from families of high income groups received 10,580 I.U. from animal and 4960 I.U. from plant sources. It was not

\footnotetext{
1 Member of the Naval Unit at the Hospital of The Rockefeller Institute for Medical Research.

2 The Bureau of Medicine and Surgery does not necessarily endorse views or opinions expressed in this paper.

3 The work reported in this communication was supported in part by the W. K. Kellogg Fund.

International units.
}

demonstrated, however, that a deficiency in this single component of the diet bore a causal relationship to rheumatic attacks (1). The purpose of the present paper is to record the results of further study of the relation of vitamin A to the rheumatic state.

\section{METHODS}

Concentrations of vitamin $\mathrm{A}$ and carotene in plasma were determined by Kimble's modification (2) of the method of Dann and Evelyn; the Evelyn photoelectric colorimeter was used in these determinations. To 5 cc. of blood plasma in a $25 \mathrm{cc}$. centrifuge tube with a ground glass stopper, an equal volume of 95 per cent ethyl alcohol was added to precipitate the proteins. Extraction of vitamin $A$ and carotene was accomplished by the addition of 12 cc. of petroleum ether. The glass stopper was inserted and sealed with a drop of mineral oil. The tube was inverted repeatedly for a period of 10 minutes and cehtrifuged at 1000 R.P.M. Ten cc. of the petroleum ether layer were removed and the carotene was determined directly in the photoelectric colorimeter by means of color filter No. 440 and a petroleum ether blank. The concentration was ascertained by reference of the galvanometer reading to a standard curve, prepared from known concentrations of crystalline carotene, containing 90 per cent beta and 10 per cent alpha carotene. After reading the value of the carotene color, the petroleum ether extract was evaporated to dryness in a stream of warm air in a water bath at $45^{\circ} \mathrm{C}$. The residue was dissolved in $1 \mathrm{cc}$. of chloroform and $9 \mathrm{cc}$. of 25 per cent antimony trichloride in chloroform were added. Since the blue color of the test fades rapidly, it was developed with the tube in the colorimeter block. The maximum value of the color was read with filter No. 620 and against a blank of 25 per cent antimony trichloride in chloroform. Values of vitamin A were obtained from a standard curve prepared by use of a distillate of the vitaminin natural ester 1 per cent

form. E 328 of this preparation had been determined to $1 \mathrm{~cm}$.

1 per cent

be equal to 114.8 and the conversion value of $\mathrm{E} 328=1$

$1 \mathrm{~cm}$.

was 1850 I.U. vitamin A. The blue color produced by the plasma carotene was corrected for by a factor relating 
the intensity of the color produced by antimony trichloride to a known concentration of crystalline carotene. The method gave reproducible results and only small percentage errors on duplicate determinations. The blood samples on which the determinations were made were not fasting samples but were taken in the morning 2 to 4 hours following the morning meal. Kimble (2) has shown that ordinary meals cause no measurable increase in the concentration of vitamin A or carotene of the plasma within 2 to 6 hours of ingestion. May, Blackfan, McCreary, and Allen (3) found very little diurnal variation in the blood level of vitamin A or carotene of subjects on usual diets.

Erythrocyte sedimentation rates were determined frequently on all of the patients with acute rheumatic fever. The method of Westergren (4) was used.

\section{RESULTS}

\section{Estimation of vitamin $A$ in diets}

The necessity of caution in relying upon dietary histories in a survey of this kind was appreciated (5). There are probably discrepancies between food actually consumed and the amount recorded by the subject. It is believed, however, that errors occurring in this study appear throughout in a truly random manner. The objective of obtaining a week's record of all food ingested by each subject was explained to a responsible member of every family cooperating in the study. Families were requested not to alter their diets in any way. Visits were made by a trained field worker during meal hours and, when cooperation seemed satisfactory, forms were left to be filled in after each meal. These forms with simple instructions for recording the kinds and amounts of food consumed, were prepared by a dietitian who assisted in the dietary analysis. From the data collected, the vitamin A consumed was calculated according to published compilations $(6,7)$. Vitamin preparations, used in reinforcing the diets, were included in the calculations. The excess or deficiency for each individual was computed by comparison with the requirements for age and sex of the child, as proposed by the National Research Council (8).

\section{The relation of levels of vitamin $A$ and carotene in the plasma to vitamin $A$ ingested}

Levels of vitamin A and carotene in the plasma were determined on 4 groups of subjects whose intakes of vitamin A had been calculated. The first of these groups included 12 normal children, of families in the high income class. The average daily intake was 109 per cent above the recommended amount for age and sex. The other 3 groups were composed of rheumatic children, no longer evidencing signs of disease activity, but on diets containing varying quantities of vitamin A. In the second group were 24 children who received more than required amounts of vitamin $\mathrm{A}$, their diets averaging 23 per cent above the calculated requirements. Forty-six subjects made up the third group. They received vitamin $\mathrm{A}$ in adequate amounts

TABLE I

The relation between diet and the plasma level of vitamin $A$ and carotene

\begin{tabular}{|c|c|c|c|c|c|c|c|c|}
\hline Subjects & $\begin{array}{l}\text { Number } \\
\text { of } \\
\text { subjects }\end{array}$ & $\begin{array}{c}\text { Vitamin } A \\
\text { in } \\
\text { plasma, } \\
\text { high } \\
\text { level }\end{array}$ & $\begin{array}{c}\text { Vitamin A } \\
\text { in } \\
\text { plasma, } \\
\text { low } \\
\text { level }\end{array}$ & $\mid \begin{array}{c}\text { in } \\
\text { plasma, } \\
\text { median } \\
\text { level }\end{array}$ & $\begin{array}{c}\text { Carotene } \\
\text { in } \\
\text { plasma. } \\
\text { high } \\
\text { level }\end{array}$ & $\begin{array}{c}\text { Carotene } \\
\text { in } \\
\text { plasma, } \\
\text { low } \\
\text { level }\end{array}$ & $\begin{array}{c}\text { Carotene } \\
\text { in } \\
\text { plasma, } \\
\text { median } \\
\text { level }\end{array}$ & Intake of vitamin A \\
\hline $\begin{array}{l}\text { 1. Diets high in vita- } \\
\text { min A } \\
\text { Normal children }\end{array}$ & 12 & 194 & $\begin{array}{c}U . \operatorname{per} 100 \mathrm{c} \\
116\end{array}$ & 139 & 0.258 & $\begin{array}{c}\text { gm. per cent } \\
0.060\end{array}$ & 0.136 & $\begin{array}{l}+109 \text { per cent of ca } 1- \\
\text { culated requiremen ts }\end{array}$ \\
\hline $\begin{array}{l}\text { 2. Diets high in vita- } \\
\text { min A } \\
\text { Rheumatic children }\end{array}$ & 24 & 204 & 84 & 132 & 0.319 & 0.088 & 0.154 & $\begin{array}{l}+23 \text { per cent of cal- } \\
\text { culated requiremen ts }\end{array}$ \\
\hline $\begin{array}{l}\text { 3. Diets adequate in } \\
\text { vitamin A } \\
\text { Rheumatic children }\end{array}$ & 46 & 180 & 65 & 108 & 0.223 & 0.043 & 0.112 & $\begin{array}{l}+5 \text { per cent of calcu- } \\
\text { lated requirements }\end{array}$ \\
\hline $\begin{array}{l}\text { 4. Diets low in vita- } \\
\text { min A } \\
\text { Rheumatic children }\end{array}$ & 25 & 168 & 41 & 93 & 0.132 & 0.033 & 0.084 & $\begin{array}{l}-44 \text { per cent of cal- } \\
\text { culated requirements }\end{array}$ \\
\hline
\end{tabular}




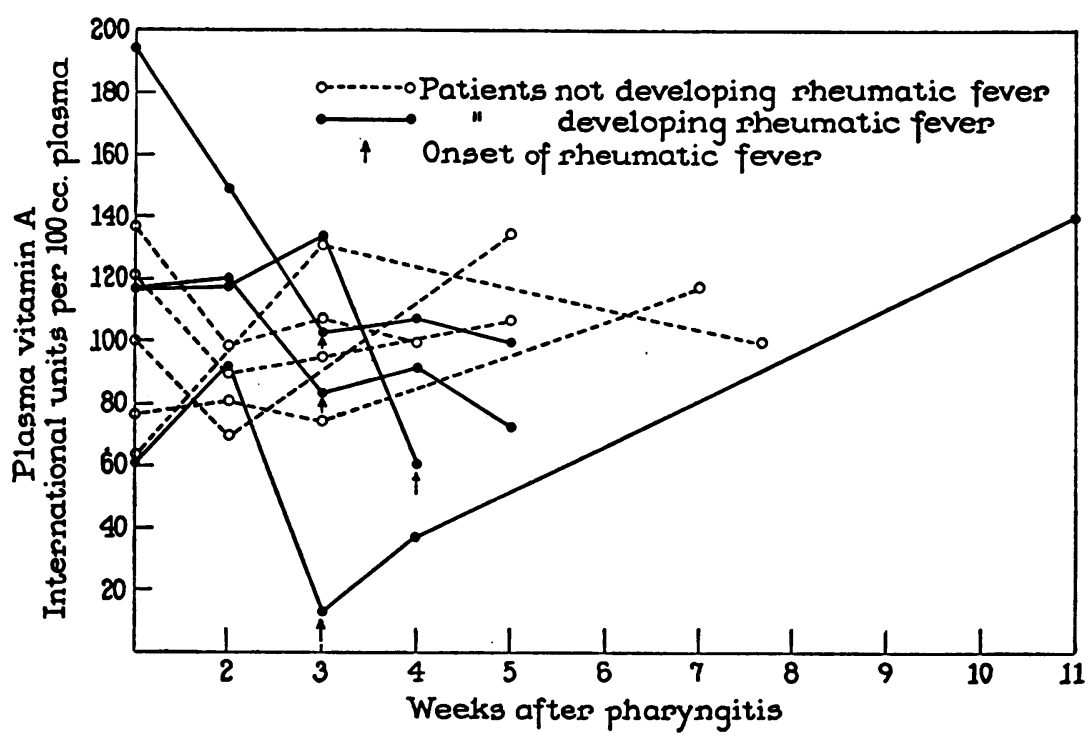

Fig. 1. Levels of Vitamin A in Plasma following Acute Pharyngitis and at the Onset of Acute Rheumatic Fever

with an average intake 5 per cent in excess of requirements. The fourth group included 25 children on low levels of intake, the average for the group being 44 per cent less than the optimum intake. The relation between intake and concentration of the vitamin and carotene in the plasma of these 4 groups is shown in Table I.

Although the range of concentration in each group was wide, the data in Table I show that there is a relationship between intake of vitamin $A$ and its level in the plasma. The subjects of the first 3 groups, whose diets contained more than the required amounts of vitamin $A$, had plasma concentrations which, with but few exceptions, fell in the range of 100 to 200 I.U. per $100 \mathrm{cc}$. plasma. When the dietary intake exceeded the required amount, there was not a proportionate increase of vitamin $A$ in the plasma. Most of the subjects in Group 4, who were on poor diets, containing only 56 per cent of the recommended daily intake, had levels below 100 I.U. per 100 cc. plasma.

Concentrations of carotene in the plasma varied widely in each of the 4 groups of subjects. However, the range of concentration was smallest in Group 4 and the median level was $0.084 \mathrm{mgm}$. per cent for this group, compared with 0.136 mgm. per cent, $0.154 \mathrm{mgm}$. per cent, and 0.112 mgm. per cent, median levels for Groups 1, 2' and 3 , respectively. Therefore, in the groups of subjects studied, the concentration of vitamin $A$ and of carotene in the plasma was lowest in the group whose diets contained the smallest quantities of vitamin $A$.

\section{The relation of levels of vitamin $A$ in the plasma to the development of rheumatic fever}

Repeated determinations of vitamin $A$ in the plasma were made on 9 rheumatic children during periods of pharyngitis caused by Group A beta hemolytic streptococci and for several weeks following recovery. Five of these children failed to develop a recrudescence of rheumatic fever while 4 manifested signs of acute rheumatism about 3 weeks following the onset of the infection of the respiratory tract. The curves of cpncentrations of vitamin $\mathrm{A}$ in the plasmas of these 9 patients are presented in Figure 1.

In Figure 1, it is seen that patients with acute pharyngitis had low levels of plasma vitamin A during the acute infection, and that with recovery, these levels increased. The onset of rheumatic activity in 4 subjects was accompanied in each case by a fall in the concentration of vitamin $A$ in the plasma to a level lower than that which was found during acute pharyngitis. 
The relation of levels of vitamin $A$ and carotene in the plasma to rheumatic activity

Frequent determinations were made of the concentration of vitamin $A$ and carotene in the plasma of 57 children with rheumatic activity. The degree of intensity of the disease was classified as being severe, mild, subsiding, or convalescent, according to commonly accepted clinical signs and laboratory findings. The results are shown in Table II.

It is seen from the results in Table II that values for vitamin $A$ in the plasma were lowest in those patients exhibiting greatest rheumatic activity. During less severe attacks, levels of vitamin A were also low. Low levels in the plasma were not always associated with pyrexia; many of the patients with severe attacks were afebrile when blood samples were obtained. Although there was a wide range of concentration during the periods of subsiding rheumatism and convalescence, the concentration tended to return gradually to normal. Throughout the course of the disease, the changes in level of vitamin $A$ in the plasma were inverse to the changes in the rate of sedimentation of erythrocytes, plasma concentration of vitamin A being low when sedimentation rates were high and increasing with decreasing sedimentation rates. Patients included in the group with most severe attacks of rheumatic fever had sedimentation rates greater than $40 \mathrm{~mm}$. per hour. The rates in the patients with mild attacks fell between 20 and $40 \mathrm{~mm}$. per hour, while in the patients in whom the disease was subsiding, they did not exceed $20 \mathrm{~mm}$. per hour. In the convalescent patients, the sedimentation rate was less than $15 \mathrm{~mm}$. per hour. There was no correlation between concentration of carotene in the plasma and the activity of the rheumatic process, median levels being very nearly the same in severe, mild, subsiding, and convalescent phases of the disease.

\section{Excretion of vitamin $A$ in the urine and changes in levels of vitamin $A$ in the plasma following large single doses of carotene and of vitamin $A$ in patients with rheumatic fever}

The results of this study have shown that there is a relationship between rheumatic activity and low concentration of vitamin $A$ in the plasma and that the blood level of this vitamin falls abruptly with the onset of acute rheumatic fever. It was assumed, therefore, that in acute rheumatic fever there is a deviation from normal in the metabolism of vitamin A. To investigate this change, further studies were made of vitamin A excreted in the urine and also of changes in levels in the plasma following large single doses of carotene and vitamin A. The patients with acute rheumatic fever were receiving therapeutic doses of salicylates when these tests were done. Both the normal subjects and the rheumatic patients were permitted their usual meals on the days that test doses of carotene and vitamin A were given. Only small portions of butter, cream, and other fatty foods were allowed on these days, however.

Vitamin A is not found in the urine of normal subjects (9) but has been found in the urine of women during pregnancy $(10,11)$ and of patients with chronic nephritis, nephrosis, cirrhosis of the liver, cholecystitis, pneumonia before crisis, tuberculosis, and cancer ( 9 to 12 ). Urine speci-

TABLE II

The relation between rheumatic activity and the plasma levels of vitamin $A$ and carotene

\begin{tabular}{|c|c|c|c|c|c|c|c|}
\hline $\begin{array}{l}\text { Intensity of } \\
\text { rheumatic } \\
\text { activity }\end{array}$ & $\begin{array}{c}\text { Number } \\
\text { of } \\
\text { patients }\end{array}$ & $\begin{array}{l}\text { Vitamin A } \\
\text { in plasma, } \\
\text { high level }\end{array}$ & $\begin{array}{c}\text { Vitamin A } \\
\text { in plasma, } \\
\text { low level }\end{array}$ & $\begin{array}{l}\text { Vitamin A } \\
\text { in plasma, } \\
\text { median level }\end{array}$ & $\begin{array}{c}\text { Carotene } \\
\text { in plasma, } \\
\text { high level }\end{array}$ & $\begin{array}{l}\text { Carotene } \\
\text { in plasma, } \\
\text { low level }\end{array}$ & $\begin{array}{c}\text { Carotene } \\
\text { in plasma, } \\
\text { median level }\end{array}$ \\
\hline Severe & 16 & \multicolumn{3}{|c|}{$\begin{array}{c}I . U . \operatorname{per} 100 \mathrm{cc} . \\
0\end{array}$} & \multicolumn{3}{|c|}{$\begin{array}{c}m g m . \text { per cent } \\
0.036\end{array}$} \\
\hline Mild & 11 & 103 & 52 & 75 & 0.154 & 0.067 & 0.092 \\
\hline Subsiding & 18 & 156 & 61 & 88 & 0.221 & 0.017 & 0.108 \\
\hline Convalescent & 12 & 162 & 33 & 93 & 0.120 & 0.092 & 0.101 \\
\hline
\end{tabular}


mens from 6 children with rheumatic fever were collected for periods of 24 ?hours and determinations made of vitamin A according to a modification of the method described for the determination of the vitamin in the blood (9). Each of these specimens contained traces of substances which gave a blue color with antimony trichloride, but in no instance was there more than that given by 20 I.U. of vitamin A excreted in a 24-hour period.

In order to study the changes brought about in the concentration of vitamin $A$ in the plasma by large single doses of carotene and vitamin $A$, test doses of these substances were given to rheumatic and to normal children. Carotene in oil was given orally to 4 patients with acute rheumatism and to 4 normal children; a test dose, representing 200,000 I.U. of vitamin A activity, was administered to each subject. Levels of carotene and of vitamin A in the plasma were determined immediately prior to the ingestion of the test dose and at periods of $2,4,6$, and 24 hours afterward. Although concentrations of plasma carotene were slightly increased after 24 hours, there were no significant changes in levels of vitamin A either in the rheumatic patients or in the normal children. Therefore, it was not possible to study the rate of conversion of carotene to vitamin $A$ in these patients by this means.

To 7 children with rheumatic fever and to 6 normal children, 200,000 I.U. of vitamin A, as a distillate in the form of the natural ester, were given by mouth. Levels of vitamin $A$ in the plasma were determined prior to the administration of the test dose and at intervals during the following 24-hour period. The results are presented in Figure 2.

Highest concentrations of vitamin A were reached in from 5 to 8 hours after the administration of the test dose of the vitamin (Figure 2). In normal children, the peak concentrations fell between 1340 and 2400 I.U. per 100 cc. plasma. In rheumatic fever patients, highest levels were from 274 to 1150 I.U. per 100 cc. plasma. This would seem to indicate a decreased rate of absorption of vitamin $A$ from the intestinal tract or an increased rate of removal from the plasma in rheumatic fever.

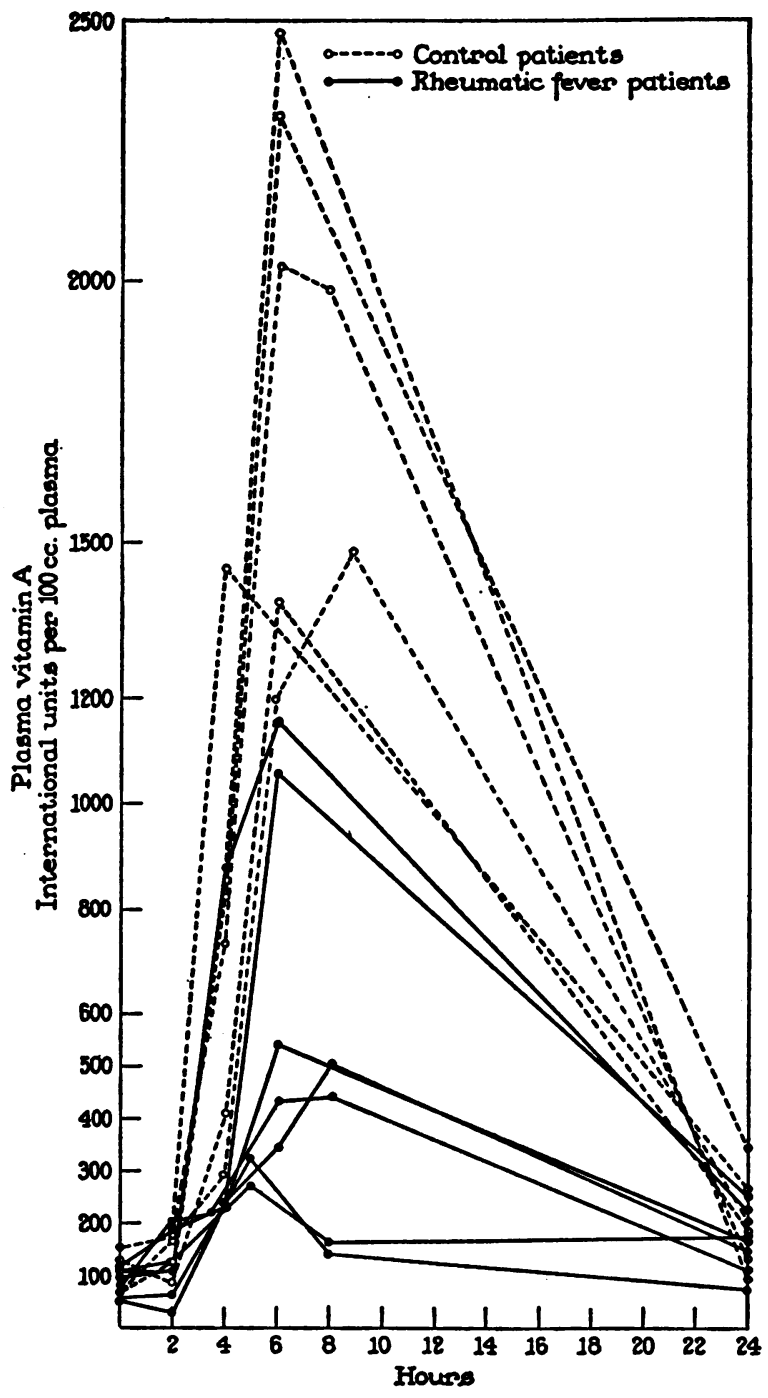

Fig. 2. Plasma levels of Vitamin A following Administration of 200,000 I.U. Vitamin A by Mouth

\section{DISCUSSION}

In an earlier report (1), dietary analyses had shown that there was a statistically significant association between susceptibility to rheumatic fever and inadequate intake of vitamin $A$ in the diet. The incidence of rheumatic fever is greatest in individuals of the low income groups. The lack of information concerning dietary requirements and the relatively high cost of foods rich in vitamin A probably account for the deficiencies in the diets of persons in these economic groups. In the studies reported in this paper, it was found that children who were susceptible 
to rheumatic fever and who were on diets containing adequate amounts of vitamin $A$ had concentrations of vitamin $\mathrm{A}$ and carotene in the plasma comparable to those of normal children on adequate intake. The rheumatic children whose diets did not provide vitamin $A$ in required amounts had low concentrations of the vitamin and of carotene in the blood plasma. May, Blackfan, McCreary, and Allen (3) and Josephs, Baber, and Conn (13) previously reported low levels in normal children on inadequate diets.

During pharyngitis caused by Group A beta hemolytic streptococci, the concentration of vitamin $A$ in the plasma of rheumatic subjects was low. With subsidence of the pharyngitis, the concentration increased but dropped again to low levels if acute rheumatic fever ensued. The lowest levels of vitamin A were found in patients with the most severe attacks of rheumatic fever. There was a gradual increase in the vitamin A level in the plasma during recovery from the rheumatic attack. Blood carotene concentrations were not significantly changed by disease activity. The mechanism which brings about these changes in concentration of vitamin $A$ in the plasma was not revealed. However, it was found that test doses of vitamin A, given by mouth, produced less increase in the concentration of vitamin A in the plasma of children with acute rheumatic fever than in normal subjects. There was no loss of unusual amounts of the vitamin in the urine.

It is known that in pneumonia and in other acute infections $(3,14$ to 17$)$, both the level in the blood and the concentration of vitamin $A$ stored in the liver are decreased. Ellison and Moore (17) determined the reserves of vitamin A stored in the liver in 200 children dying by accident or from various diseases and found the lowest reserves in children dying of valvular diseases of the heart. The requirements for vitamin A are increased in thyrotoxicosis (18) and in pregnancy (19). Fever, produced artificially (20), is accompanied by a decrease in the concentration of the vitamin in the plasma. It would seem, therefore, that conditions resulting in increased demands on general body metabolism are accompanied by a decrease in plasma level of vitamin $A$. Whether vitamin $A$ is destroyed in some abnormal manner in these conditions, or whether it is utilized in normal metabolic processes but with increased velocity, can be determined only when more knowledge is available concerning the mode of action of vitamin $\mathrm{A}$.

\section{SUMMARY}

1. The level of vitamin $A$ and carotene in the plasma is related to the intake of vitamin $A$ in the diet of rheumatic subjects.

2. Irrespective of the concentration prior to the onset of disease activity, there is a fall in the level of vitamin $A$ in the plasma with the development of acute rheumatic fever. The concentration of carotene in the plasma is not significantly changed during rheumatic attacks.

3. The degree of decrease of vitamin $A$ in plasma varies directly with the intensity of the rheumatic attack. In severe attacks, concentrations in the plasma varied between 0 and 70 I.U. of vitamin A per $100 \mathrm{cc}$. plasma.

4. Patients with rheumatic fever show delayed or decreased absorption of vitamin A or metabolize it in an abnormal manner.

\section{BIBLIOGRAPHY}

1. Coburn, A. F., and Moore, L. V., Nutrition as a conditioning factor in the rheumatic state. Am. J. Dis. Child., 1943, 65, 744.

2. Kimble, M. S., The photocolorimetric determination of vitamin $\mathrm{A}$ and carotene in human plasma. J. Lab. and Clin. Med., 1939, 24, 1055.

3. May, C. D., Blackfan, K. D., McCreary, J. F., and Allen, F. H., Jr., Clinical studies of vitamin A in infants and in children. Am. J. Dis. Child., 1940, $59,1167$.

4. Westergren, A., The technique of the red cell sedimentation reaction. Am. Rev. Tuberc., 1926, 14, 94.

5. Huenemann, R. L., and Turner, D., Methods of dietary investigation. J. Am. Dietet. A., 1942, 18, 562.

6. Chatfield, C., and Adams, G., Proximate composition of American food materials. U. S. Dept. of Agri. Circular No. 549, 1940.

7. Bowes, A. D., and Church, C. F., Food Values of Portions Commonly Served. Philadelphia Child Health Society, Phila., Pa., 1938.

8. Recommended daily allowances for specific nutrients. J. A. M. A., 1941, 116, 2601.

9. Lawrie, N. R., Moore, T., and Rajagopal, K. R., The excretion of vitamin A in urine. Biochem. J., 1941, 35,825 . 
10. Gaehtgens, G., Uber die Ausscheidung von Vitamin A in der Gravidität. Klin. Wchnschr., 1937, 16, 52.

11. Schneider, E., and Weigand, H., Die krankhafte Vitamin A-Ausscheidung im Harn. Klin. Wchnschr., 1937, 16, 441.

12. Boller, R., and Brunner, O., Über die Ausscheidung von Vitamin A im Harn. Klin. Wchnschr., 1937, 16, 861.

13. Josephs, H. W., Baber, M., and Conn, H., Studies in vitamin A-Relation of blood level and adaptation to dim light to diet. Bull. Johns Hopkins Hosp., 1941, 68, 375.

14. Clausen, S. W., Limits of the anti-infective value of provitamin A (carotene). J. A. M. A., 1933, 101, 1384.

15. Lewis, J. M., Bodansky, O., and Haig, C., Level of vitamin $A$ in the blood as an index of vitamin $A$ deficiency in infants and in children. Am. J. Dis. Child., 1941, 62, 1129.

16. Nylund, C. E., and With, T. K., On the demonstration of vitamin A deficiency in man. Acta Med. Scandinav., 1941, 106, 202.

17. Ellison, J. B., and Moore, T., The vitamin A reserves of the human infant and child in health and disease. Biochem. J., 1937, 31, 165.

18. Wendt, H., Hypercholesterinämie und Vitamin A. Deutsche med. Wchnschr., 1936, 62, 1213.

19. Edmund, C., and Clemmesen, S., On Deficiency of A Vitamin and Visual Dysaptation. II. Levin and Munksgaard, Copenhagen, 1937.

20. Thiele, W., and Scherff, I., Der Serum-Vitamin ASpiegel im Fieber. Klin. Wchnschr., 1939, 18, 1275. 